\title{
AOR
}

Selected Papers of \#AolR2020:

The 22nd Annual Conference of the

Association of Internet Researchers

Virtual Event / 13-16 Oct 2021

\section{INDEPENDENT OVERSIGHT, DATA GOVERNANCE AND THE TEMPORAL CONSTRUCTION OF FORENSIC EVIDENCE: THE MAKING OF THE FIRST STATEWIDE RAPE KIT TRACKING PLATFORM}

\author{
Renee Shelby \\ Northwestern University
}

Across the US, police management of sexual assault kits (SAKs) has led to systemic disorganization resulting in lost, forgotten, and abandoned forensic evidence. In response, victim advocates champion "sexual assault kit tracking platforms" as a pillar of survivor-centered and trauma-informed approaches to rape kit reform at the state level and to create independent oversight over forensic processes. In January 2017, Idaho became the first state to fully implement a statewide tracking platform. The Idaho Sexual Assault Kit Tracking System (IKTS) allows survivors, medical and legal actors, and the broader public to track kits from distribution through the collection, testing, and retention process at law enforcement facilities. As of 2020, five other jurisdictions (New York, Ohio, North Carolina, Utah, and Puerto Rico) have adopted the open-source IKTS software. While a major step in confronting the systemic disorganization of evidence, the emergence of statewide tracking platforms raises urgent questions about what governance paradigms, data relations, and discourses are enabled through these systems.

The aim of this research is to uncover which paradigms, relations, and discourses have emerged through the development and implementation of the first statewide sexual assault kit tracking platform. Broadly, three research questions guide this paper: (1) How are discourses of "evidence" constructed in the legislative debate about IKTS? (2) What data relationships and governance paradigms do evidentiary discourses in IKTS enable? (3) How do evidentiary discourses draw on race, gender, and sexuality systems for meaning in IKTS? Using insights from critical race theory and feminist science and technology studies, I answer these questions through a discursive analysis of three state laws governing IKTS and sexual assault forensic evidence (HB528, HB146, and HB116), legislative committee hearings, annual reports to the legislature, IKTS protocols, and media coverage of Idaho's backlog between 2010 and 2020. Rather than "victim's rights" or "perpetrator accountability," I find concerns about "timeliness" and the temporal life of forensic evidence structured the creation, deployment, and maintenance of IKTS. I argue that timeliness is a data governance

Suggested Citation (APA): Shelby, R.. (2021, October). Independent Oversight, Data Governance and the Temporal Construction of Forensic Evidence: The Making of the First Statewide Rape Kit Tracking Platform. Paper presented at AolR 2021: The 22nd Annual Conference of the Association of Internet Researchers. Virtual Event: AolR. Retrieved from http://spir.aoir.org. 
paradigm with multiple and shifting meanings of temporality that comprise various legal, social, and data relationships. I show how constructions of time and timeliness are used to discipline the network of state actors responsible for stewarding forensic evidence, including medical examiners, police, prosecutors, and the crime lab. The discourse of tardy, slow, and untimely forensic evidence is an organizing principle to codify consistent statewide forensic practice, increase transparency, centralize legal decision making, and generate a steady stream of forensic data into CODIS, the national DNA database.

The legislature's treatment of SAK disorganization as a problem of unmanaged "temporality" assumes a view of evidence processing decisions as neutrally unmechanized and unstandardized. On one hand, this treatment of evidence as temporal obscures how gender and racialized rape myths have long shaped law enforcement decision making; on the other, IKTS protocols do offer some intervention into such sexist and racist legal practices. I argue this intervention should not be read as signs of a racial justice technofix, but rather as indications of the limits and possibilities of the "techno-legal response to sexual assault" as a method of state accountability. 